\title{
KAJIAN YURIDIS TENTANG IMPLEMENTASI JAMINAN KESEHATAN BAGI WARGA MISKIN DAN/ATAU TIDAK MAMPU DI KOTA SEMARANG
}

\author{
Amelia Rizky Budiyanto, Muzayanah \\ Fakultas Hukum, Universitas Stikubank (UNISBANK) Semarang \\ E-mail: ameliarizky9@gmail.com, muzayanah@edu.unisbank.ac.id
}

\begin{abstract}
ABSTRAK
Berdasarkan pasal $28 \mathrm{H}$ ayat (1) Undang-Undang Dasar 1945. Pemerintah Daerah memiliki tanggung jawab untuk memenuhi hak atas layanan kesehatan warganya sehingga warganegara berhak mendapatkan layanan kesehatan. Dengan demikian Pemerintah Kota Semarang mengesahkan Peraturan Walikota Semarang Nomor 43 Tahu 2017 tentang Penyelenggaraan Jaminan Kesehatan. Fakir Miskin an anak terlantar di pelihara oleh negara, hal itu tertuang pada pasal 34 ayat (1) Undang-Undang Dasar 1945. Melalui program UHC, Pemerintah Kota Semarang memberikan pelayanan kesehatan pada warganya. Tujuan penelitian ini adalah untuk mengetahui pelaksanaan jaminan kesehatan terutama bagi warga miskin dan tidak mampu demi meningkatkan derajat kesehatan masyarakat. Tipe penelitian ini menggunakan metode yuridis-normatif, yaitu dengan menggambarkan peraturan perundang-undangan yang berlaku dikaitkan dengan teori-teori hukum dan praktek pelaksanaan hukum positif yang berkaitan dengan permasalahan. Penelitian yuridis-normatif sesuai dengan penelitian yang dilakukan oleh penulis, karena dalam penelitian ini penulis berusaha menguraikan kenyataan-kenyataan yang ada atau fakta yang ada dan mendeskripsikan sebuah masalah yang terdapat pada pelaksanaan Peraturan Walikota Semarang No 43 Tahun 2017 tentang Penyelenggaraan Jaminan Kesehatan. Dengan adanya PBI maupun UHC hal itu telah membantu masyarakat dari segi biaya, namun perlu ditambahkan bahwa Perwal Kota Semarang Nomor 43 Tahun 2017 tersebut belum mengatur lebih rinci mengenai untuk rawat jalan sehingga masih menimbulkan beban biaya yang dirasakan oleh masyarakat. Dan juga pemerintah masih perlu melakukan sosialisasi mengenai program UHC, terbukti di tahun ke-3 (tiga) program tersebut berjalan masih ada masyarakat yang belum mengetahui program tersebut. Sayang rasanya bilamana program tersebut manfaatnya belum bisa dirasakan oleh masyarakat secara keseluruhan.
\end{abstract}

Kata kunci: Implementasi, Jaminan Kesehatan, Warga Miskin 


\begin{abstract}
Based on Article $28 \mathrm{H}$ paragraph (1) of the 1945 Constitution. Local governments have the responsibility to fulfill the right to health services for their citizens so that citizens have the right to health services. Thus the Semarang City Government ratified Semarang Mayor Regulation Number 43 of 2017 concerning the Implementation of Health Insurance. The poor and neglected children are cared for by the state, this is stated in article 34 paragraph (1) of the 1945 Constitution. Through the UHC program, the Semarang City Government provides health services to its citizens. The purpose of this study was to determine the implementation of health insurance, especially for the poor and underprivileged in order to improve the public health status. This type of research uses the juridical-normative method, namely by describing the prevailing laws and regulations associated with legal theories and practice of implementing positive law relating to problems. Juridical-normative research is in accordance with the research conducted by the author, because in this study the writer tries to describe the existing facts or existing facts and describe a problem that exists in the implementation of Semarang Mayor Regulation No. 43 of 2017 concerning the Implementation of Health Insurance. With the existence of PBI and UHC, it has helped the community in terms of costs, but it should be added that the Semarang City Regulation Number 43 of 2017 has not regulated in more detail regarding outpatient care so that it still causes a cost burden felt by the community. And also the government still needs to disseminate information about the UHC program, as evidenced in the 3rd (third) year the program is running there are still people who do not know about the program. It is a shame that the benefits of this program cannot be felt by the community as a whole.
\end{abstract}

Keywords: Implementation, Health Insurance, The Poor 


\section{Pendahuluan}

Hak Asasi Manusia atau HAM adalah hak dasar yang dimiliki setiap manusia di seluruh dunia. Hak ini muncul sejak manusia itu terlahir dan hidup di dunia. HAM melekat pada diri manusai. Hak manusia tidak tergantung pada pemberian orang lain, masyarakat, bahkan negara. Bisa dikatakan hak manusia tercipta dari Tuhan Yang Maha Esa.

Manusia terlahir dengan martabat tinggi, punya akal dan pikiran, berkedudukan lebih tinggi dibanding ciptaan lain seperti hewan dan tumbuhan. Oleh sebab itu hak bersifat universal, yang berarti berlaku di mana saja, kepada atau untuk siapa saja, dan tidak bisa diambil oleh orang lain.

Salah satunya kesehatan. Kesehatan merupakan salah satu kebutuhan yang dibutuhkan oleh seseorang. Dengan kondisi badan yang sehat orang tersebut dapat melakukan aktivitas untuk menompang kebutuhan hidupnya. Namun apabila orang tersebut mendapatkan sebuah sakit maka mendapatkan layanan kesehatan adalah hak orang tersebut.

Layanan kesehatan merupakan hak yang harus didapatkan ketika seseorang merasa tubuhnya tak sehat dan negara wajib memenuhi hak tersebut. Mendapatkan pelayanan kesehatan merupakan hak setiap warga negara Indonesia di mana hal itu tertuang pada pembukaan Undang-Undang Dasar 1945 alenia ke-4, "Kemudian daripada itu untuk membentuk suatu Pemerintah Negara Indonesia yang melindungi segenap bangsa Indonesia dan seluruh tumpah darah Indonesia dan untuk memajukan kesejahteraan umum, mencerdaskan kehidupan bangsa, dan ikut melaksanakan ketertiban dunia yang berdasarkan kemerdekaan, perdamaian abadi dan keadilan sosial, maka disusunlah Kemerdekaan Kebangsaan Indonesia itu dalam suatu UndangUndang Dasar Negara Indonesia, yang terbentuk dalam suatu susunan Negara Republik Indonesia yang berkedaulatan rakyat dengan berdasar kepada Ketuhanan Yang Maha Esa, Kemanusiaan yang adil dan beradab, Persatuan Indonesia dan Kerakyatan yang dipimpin oleh hikmat kebijaksanaan dalam Permusyawaratan/Perwakilan, serta dengan mewujudkan suatu Keadilan sosial bagi seluruh rakyat Indonesia." Dimana yang dimaksud dengan keadailan sosial adalah suatu keadaan yang mana semua warga negara mendapatkan haknya, seperti yang tertuang dalam pasal $28 \mathrm{H}$ ayat (1) yang mengatakan bahwa: "Setiap orang berhak hidup sejahtera lahir dan batin, bertempat tinggal, dan mendapatkan lingkungan hidup yang baik dan sehat serta berhak memperoleh pelayanan kesehatan". Selanjutnya dalam pasal 34 ayat

UUD 1945 mengatakan bahwa: "Negara mengembangkan sistem jaminan sosial bagi seluruh rakyat dan memberdayakan masyarakat lemah dan tidak mampu sesuai dengan martabat kemanusiaan".

Pemerintah telah berupaya memberikan pelayanan kesehatan kepada masayarakat melalui program-program yang telah direncanakan. Jaminan sosial adalah salah satu salah satu program yang diselenggarakan oleh pemerintah untuk warga negaranya agar mendapatkan kebutuhan hidup yang layak. Fakir miskin dan anak terlantar di pelihara oleh negara, hal itu sesuai 
dengan bunyi pasal 34 ayat (1) UndangUndang Dasar 1945. Melalui berbagai peraturan yang ada, pemerintah berupaya mewujudkan program jaminan kesehatan yang adil dan merata.

Pemerintah pusat bekerja sama dengan pemerintah daerah untuk melaksanakan dan mewujudkan program jaminan kesehatan yang adil dan merata. Dengan adanya kerja sama hal itu sesuai dengan asas desentralisasi, di mana pemerintah pusat menyerahkan kebijakan kepada pemerintah daerah untuk mengatur rumah tangganya sendiri namun tetap ada koordinasi dengan pemerintah pusat. Maka dari itu Pemerintah Kota Semarang mengesahkan Peraturan Walikota Nomor 43 Tahun 2017 tentang Penyelenggaraan Jaminan Kesehatan sebagai landasan diberlakukannya pelayanan jaminan kesehatan di Kota Semarang. Melalui Perwal tersebut Pemerintah Kota Semarang berupaya memberikan jaminan kesehatan yang terjamin dan terjangkau, bertujuan untuk menjamin agar warganya memperoleh pemeliharaan jaminan kesehatan dalam memenuhi kebutuhan hidup dasar dan mengatur segala sesuatu yang berkaitan dengan pelayanan kesehatan yang diberikan pada masyarakatnya. Mulai dari jenis peserta jaminan kesehatan hingga monitoring dan evaluasi tertuang dalam Perwal tersebut dimana warga miskin dan tidak mampu menjadi salah satu fokus Pemerintah Kota Semarang dalam penyelenggaraan jaminan kesehatan.

Melalui program UHC, Pemerintah Kota Semarang menjamin pelayanan kesehatan warganya. UHC (Universal Health Coverage) adalah sebuah program sistem kesehatan yang memastikan setiap warga dalam memiliki akses kesehatan yang adil dan mudah dalam mendapatkan pelayanan kesehatan. Untuk mengetahui bagaimana pelaksanaan jaminan kesehatan di Kota Semarang bagi warga miskin, penulis memilih judul penelitian 'Tinjauan Yuridis Tentang Penyelenggaraan Jaminan Kesehatan Bagi warga Miskin Dan/Atau Tidak Mampu Di Kota Semarang' yang nantinya akan di bahas pada bab selanjutnya.

\section{Tujuan Penelitian}

Tujuan dari penelitian ini adalah untuk mengetahui bagaimana pelaksanaan jaminan kesehatan di Kota Semarang, pelakasanaan jaminan kesehatan bagi warga miskin serta hambatan yang ada.

\section{Rumusan Masalah}

Berdasarkan judul penelitian hukum dalam latar belakang yang diuraikan di atas maka penulis berusaha untuk mengemukakan permasalahan sebagai berikut:

1. Bagaimana penyelenggaraan jaminan kesehatan berdasarkan Perwal Kota Semarang nomor 43 tahun 2017 tentang penyelenggaraan jaminan kesehatan?

2. Bagaimana penyelenggaraan jaminan kesehatan bagi warga miskin dan/atau tidak mampu di kota Semarang?

3. Hambatan-hambatan apa saja yang dihadapi dalam melaksanakan jaminan kesehatan bagi warga miskin dan/atau tidak mampu dan bagaimana solusinya?

\section{Metode Penelitian}

Penelitian ini menggunakan pendekatan yuridis normatif. Pendekatan yuridis normatif dilakukan dengan cara menelaah dan menginterpretasikan hal-hal yang bersifat teoritis yang menyangkut asas, konsepsi, doktrin dan norma hukum yang 
berkaitan dengan hal yang di teliti.

\section{Pembahasan}

Penyelenggaraan Jaminan Kesehatan Berdasarkan Peraturan Walikota Semarang Nomor 43 Tahun 2017 Tentang Penyelenggaraan Jaminan Kesehatan. Pemerintah Daerah memiliki kewajiban untuk memberikan layanan kesehatan bagi warganya dan wajib mendukung program kesehatan yang diselenggarakan oleh pemeritah pusat, hal itu sebagai upaya untuk mewujudkan program kesehatan yang adil dan merata serta sebagai bentuk perwujudan dari asas desentralisasi, Pemerintah Kota Semarang mengesahkan Perwal Semarang Nomor 43 Tahun 2017 tentang Penyelenggaraan Jaminan Kesehatan sebagai dasar pelaksanaan jaminan kesehatan di Kota Semarang. Menurut Perwal tersebut kepesertaan jaminan kesehatan Kota Semarang di bagi menjadi dua jenis, yaitu peserta PBI jaminan kesehatan dan peserta bukan PBI jaminan kesehatan.

Di mana peserta PBI jaminan kesehatan di bagi menjadi tiga macam yaitu: Peserta PBI Jaminan Kesehatan Anggaran Pendapatan Belanja Negara (APBN) yaitu Peserta PBI yang iuran kesehatannya dibebankan pada pemerintah pusat;

Peserta PBI Jaminan Kesehatan Provinsi yaitu Peserta PBI yang iuran kesehatannya dibebankan pada Pemerintah Provinsi Jawa Tengah; Peserta PBI Jaminan Kesehatan Daerah yaitu Peserta PBI yang iuran kesehatannya dibebankan pada Pemerintah Kota Semarang.

Hal itu sesuai dengan ketentuan yang terdapat pada pasal 4 ayat (2) Perwal Semarang Nomor 43 Tahun 2017. Sedangkan untuk peserta bukan PBI jaminan di atur pada pasal 4 ayat (3), yang menyebutkan bahwa:

1. Pekerja penerima upah beserta anggota keluarganya;

2. Pekerja bukan penerima upah beserta anggota keluarganya; dan

3. Bukan pekerja dan anggota keluarganya.
Masyarakat yang termasuk dalam kategori PBI Jaminan Kesehatan apabila masyarakat tersebut tinggal di Kota Semarang minimal 6 (enam) bulan dan bukan termasuk dalam peserta Jaminan Kesehatan Nasional baik pemerintah pusat maupun pemerintah daerah, peserta jaminan kesehatan mandiri kelas I dan II yang menunggak selama 3 (bulan) berturut-turut serta jaminan kesehatan mandiri kelas III yang menunggak selama 1 (satu) bulan yang kemudian dialihkan menjadi PBI Daerah kelas III asalkan bersedia menerima layanan kesehatan tingkat pertama dan/atau ruang rawat kelas III pada pelayanan tingkat lanjut, bayi baru lahir dari peserta PBI Daerah dan yang terakhir adalah bayi baru lahir dari peserta jaminan kesehatan mandiri yang belum didaftarkan.

Ketentuan tersebut sesuai dengan pasal 5 ayat (1) dan (2) Perwal Semarang Nomor 43 Tahun 2017 tersebut. Kepesertaan jaminan kesehatan gugur apabila yang bersangkutan meninggal dunia, meningkatkan fasilitas kesehatannya ke tingkat yang lebih tinggi, merubah status kepesertaannya serta pindah kependudukan keluar dari daerah Kota Semarang. Apabila masyarakat yang masuk dalam klasifikasi PBI jaminan kesehatan daerah harus melampirkan foto copy Kartu Keluarga (KK) dan menunjukkan aslinya, foto copy KTP dan menunjukkan aslinya, foto copy akte kelahiran atau surat keterangan lahir dan menunjukkan aslinya. Sedangkan untuk peserta bukan PBI diatur lebih lanjut sesuai dengan peraturan perundang-undangan yang berlaku.

Pada pasal 8 Perwal tersebut menyebutkan bahwa masyarakat yang menjadi peserta jaminan kesehatan dengan klaim pemerintah daerah yaitu : Fakir miskin dan orang tidak mampu yang tidak teregister (orang terlantar, anak jalanan, gelandangan, pengemis dan orang dengan gangguan jiwa); penghuni panti sosial; dan penyandang masalah kesejahteraan sosial lainnya.

Dengan ketentuan klaim pemerintah daerah diberikan setelah yang bersangkutan 
memiliki surat rekomendasi dari Dinas yang menangani urusan sosial. Masyarakat yang menjadi peserta jaminan kesehatan dengan klaim Pemerintah Daerah mendapatkan pelayanan kesehatan rawat jalan dan rawat inap di fasilitas kesehatan tingkat pertama (FKTP) dan fasilitas kesehatan rujukan tingkat lanjutan (FKRTL) dengan layanan rawat inap kelas III yang bekerja sama dengan pemerintah daerah.

Berdasarkan uraian di atas dapat diketahui bahwa dasar hukum yang digunakan untuk mengatur tentang pelaksanaan jaminan kesehatan di Kota Semarang sudah sesuai dengan hierarki yang ada sehingga sesuai dengan asas hukum yang menyebutkan bahwa peraturan yang lebih rendah kedudukannya tidak boleh lebih tinggi dari peraturan yang lebih tinggi.

Penyelenggaraan Jaminan Kesehatan Warga Bagi Miskin Dan/Atau Tidak Mampu Di Kota Semarang

Di Kota Semarang pada tanggal 1 November 2017 Pemerintah Kota Semarang bersama Badan Penyelenggara Jaminan Sosial (BPJS) meluncurkan sebuah program yang bernama UHC (Universal Health Coverage). Penyelengaraan program ini ditandai dengan ditandatangani Peraturan Walikota Semarang Nomor 43 Tahun 2017 Tentang Penyelenggaraan Jaminan Kesehatan. UHC adalah sebuah sistem kesehatan yang memastikan setiap warga dalam memiliki akses yang adil dan mudah dalam mendapatkan pelayanan kesehatan. UHC memiliki tujuan sebagai berikut :

1. Menjamin masyarakat di kabupaten/kota mempunyai jaminan kesehatan.

2. Mempermudah masyarakat mengakses layanan kesehatan.

3. Untuk mendapatkan kepesertaan UHC calon peserta diharuskan datang ke Kantor Dinas Kesehatan Kota Semarang dengan persyaratan:
a. Berdomisili di Kota Semarang minimal 6 bulan
b. Ber-KTP Kota Semarang

c. Membawa KTP dan KK

d. Mau ditempatkan di pelayanan kelas III ketika harus mendapatkan pelayanan rawat inap di Rumah Sakit.

Yang diprioritaskan oleh Pemerintah Kota Semarang adalah masyarakat yang sakit dan tidak memiliki jaminan kesehatan dan masyarakat yang tidak memiliki pekerjaan. UHC yang ditargetkan untuk mencapai 95\% kini Kota Semarang telah mencapai lebih dari 95\% yaitu sebesesar 95.80\%. Yang membedakan UHC dengan BPJS Kesehatan adalah masyarakat yang mendaftar UHC maka kepesertaannya akan aktif hari peserta itu mendaftar sedangkan untuk BPJS Kesehatan harus menunggu selama 14 hari.

\section{Hambatan Dalam Pelakasanaan Jaminan Kesehatan Bagi Warga Miskin dan/atau Tidak Mampu Serta Solusi}

Dalam pelaksanaannya, banyak masyarakat yang belum mengetahui tentang UHC. Hal itu dapat disebabkan oleh pemerintah yang kurang melakukan sosialisasi pada masyarakat namun hal itu bisa terjadi juga karena masyarakat yang kurang aktif dalam mencari informasi mengenai program yang tengah dilaksanakan oleh pemerintah. Dengan adanya generasi muda di lingkungan masyarakat seharusnya dapat di harapkan menjadi perpanjangan tangan pemerintah dalam memberikan informasi kepada masyarakat, di mana itu artinya generasi muda diharuskan untuk lebih aktif lagi dalam menggali info mengenai program kerja pemerintah. Apabila generasi muda berhasil menjadi perpanjangan tangan pemerintah dalam mensosialisasikan program tersebut maka dapat diharapkan pula semakin banyak masyarakat yang mengetahuinya maka semakin banyak masyarakat yang haknya sebagai warga negara terpenuhi. 


\section{Kesimpulan}

Berdasarkan uraian dari analisis yang dilakukan oleh penulis dapat disimpulkan : Dengan diberlakukannya Peratura Walikota Semarang Nomor 43 Tahun 2017 tidak melanggar aturan hierarki yang ada dimana peraturan perundang- undangan yang lebih rendah tidak boleh bertentangan dengan peraturan perundang- undangan yang lebih tinggi. Memang ada beberapa pasal yang ada di Perwal tersebut tidak sejalan dengan perundang-undangan yang lebih tinggi di mana hal itu salah satu berjalannya asas desentralisasi.Dengan adanya Jaminan Kesehatan bagi warga miskin berupa BPJS Kesehatan dan UHC hal itu membantu warga miskin berupa keringanan biaya dalam mendapatkan layanan kesehatan.

Dengan adanya dua program tersebut masyarakat terbantu dari segi ekonomi, di mana masyarakat diringankan untuk biaya layanan kesehatan. Masih ada beberapa kendala yang dihadapi diantara berupa masyarakat yang tidak mengetahui bahwa Pemerintah Kota Semarang memiliki Program layanan kesehatan bernama UHC serta masih adanya masyarakat yang mendapatkan pelayanan yang lambat ketika berobat. Selain itu pula juga masih ada masyarakat yang merasakan beban biaya dari beberapa jenis obat yang mahal yang tidak tercover oleh pemerintah.

\section{Saran}

Untuk Pemerintah

Seusai melakukan analisis, maka dengan ini penulis memberikan saran kepada pemerintah agar lebih gencar dalam mensosialisasikan program UHC kepada masyarakat dan melengkapi instumen hukum yang ada. Program UHC adalah sebuah program yang positif dan dapat membantu masyarakat dalam mendapatkan layanan kesehatan, sayang rasanya bila mana program tersebut belum diketahui oleh masyarakat secara menyeluruh. Serta kembali mengevalusai rumah sakit-rumah sakit yang menjalin kerjasama dengan pemerintah agar dapat memberikan pelayanan kesehatan yang lebih maksimal.

Untuk Masyarakat

Pemerintah Kota Semarang telah berupaya secara maksimal agar program jaminan kesehatan yang mereka jalankan dapat tersampaikan oleh warganya. Namun sebuah program tidak ada berjalan maksimal apabila hanya satu sisi saja yang bergerak, maka dari itu penulis menyarankan kepada masyarakat khususnya generasi muda untuk aktif mencari informasi mengenai programprogram apa saja yang sedang dilaksanakan oleh pemerintah. Dengan hal itu masyarakat dapat membantu pemerintah dalam melakukan sosialisasi mengenai program tersebut.

\section{Daftar Pustaka}

\section{Literatur}

Soekanto, Soerjono, 2005, Pengantar Penelitian Hukum, UI, Jakarta, hal.52

Soerjono Suekanto \& Sri Mamudji, Penelitian Hukum Normatif (Suatu Tinjauan Singkat), Rajawali Pers, Jakarta, 2001, hlm.13-14

\section{Jurnal, skripsi atau majalah}

Yosita Melani, Dra.M. Surayaningsih, M.S. Implementasi Kartu Semarang Sehat [jurnal], Semarang (ID) : Universitas Diponegoro.

Veronica Agnes Sianipan, Edy Mulyono, Rosita Indrayanti.2014.Tinjauan Yuridis Perlindungan Hukum Hak Asasi Manusia Dalam Undang-Undang Nomor 17 Tahun 2013 Tentang Organisasi Kemasyarakatan.E- Journal Lentera Hukum.I (1): 66-67.

\section{Perundang- undangan}

Undang-Undang Dasar 1945

Undang-Undang Nomor 36 Tahun 2009 Tentang Kesehatan

Undang-Undang Nomor 40 Tahun 2004

Tentang Sistem Jaminan Sosial Nasional Undang-Undang Nomor 24 Tahun 2011 
Tentang Badan Penyelenggara Jaminan Sosial

Peraturan Pemerintah RI Nomor 101 Tahun 2012 Tenetang Penerima Bantuan Iuran Jaminan Kesehatan

Peraturan Presiden Nomor 82 Tahun 2018 tentang Jaminan Kesehatan

Peraturan Walikota Semarang Nomor 43 Tahun 2017 Tentang Penyelenggaraan Jaminan Kesehatan

\section{$\underline{\text { Website }}$}

https://id.wikipedia.org/wiki/Jaminan sosial/ https://id.wikipedia.org/wiki/Ke sehatan/ https://www.kemkes.go.id/resorces/download /jkn/himpunanperaturan-jaminankesehatan.pdf 